\title{
A Location-Allocation Model for Seaport-Dry Port System Optimization
}

\author{
Xuejun Feng, ${ }^{1}$ Yan Zhang, ${ }^{1}$ Yuwei Li, ${ }^{2}$ and Wei Wang ${ }^{1}$ \\ ${ }^{1}$ Institute of Waterborne Transportation \& Logistics Engineering, College of Harbor, Coastal and Offshore Engineering, \\ Hohai University, Nanjing, China \\ ${ }^{2}$ College of Transport \& Communications, Shanghai Maritime University, Shanghai, China
}

Correspondence should be addressed to Xuejun Feng; fxj@hhu.edu.cn

Received 28 June 2013; Revised 26 October 2013; Accepted 3 November 2013

Academic Editor: Zhigang Jiang

Copyright (C) 2013 Xuejun Feng et al. This is an open access article distributed under the Creative Commons Attribution License, which permits unrestricted use, distribution, and reproduction in any medium, provided the original work is properly cited.

\begin{abstract}
Seaports participate in hinterland economic development through partnerships with dry ports, and the combined seaport-dry port network serves as the backbone of regional logistics. This paper constructs a location-allocation model for the regional seaport-dry port network optimization problem and develops a greedy algorithm and a genetic algorithm to obtain its solution. This model is applicable to situations under which the geographic distribution of demand is known. A case study involving configuration of dry ports near the west bank of the Taiwan Strait is conducted, and the model is successfully applied.
\end{abstract}

\section{Introduction}

Rapid development of seaports and intermodal transportation systems under integrated planning has made it necessary for seaports to dynamically assess what constitutes their hinterlands, and the scramble for hinterlands by seaports is heating up. On the other hand, it is increasingly recognized by hinterlands that seaports guide and support regional economic development, and there is a growing need to perform in hinterland locations seaports' functions except ship loading and unloading. The interactions of these two driving forces have induced rapid development of dry ports as both a means by which seaports vie for hinterland access and a means by which hinterlands stimulate economic growth. Logistics networks, each including a group of seaports and some dry ports, are becoming backbones of regional goods movement. At the end of 2011, there were over 100 dry ports built or being built in China, with the Port of Tianjin leading the development of more than 20 of them. There were also a large number of road and rail transportation hubs which were in many aspects similar to dry ports. The development of dry ports can mitigate problems caused by constraints related to land and others that limit seaports' growth. Dry ports can also coordinate the operation of the port supply chain and support regional economic development. Consequently, dry ports are changing the dynamics of interaction between seaports and hinterlands. This paper studies the location of dry ports from the perspective of seaport-hinterland interaction and optimizes the configuration of the seaport-dry port system, taking into consideration the relationships between dry ports, seaports, and the regional logistics system.

On the evolution of a port, Bird [1] developed the Anyport model describing how port infrastructures develop over time and space and how the relationship between ports and their host cities evolves. Three major steps of port development were identified: setting, expansion, and specialization. Based on his study of East African ports, Hoyle [2] amended the original Anyport model and proposed a six-stage model of port development. Notteboom and Rodrigue [3] proposed that adding to the three stages in Bird's model is the stage of regionalization, during which seaports achieve development mainly through inland expansion. Rodrigue and Notteboom [4] further extended the concept of inland to include both hinterland and foreland. CEMT [5] recognized that hinterland resources would inevitably become indispensable for seaports engaging in intense market competition.

The rapid development of multimodal transportation has driven the movement of containers within inland regions. 
Since the early 1980s, operators of containerized transport have built sophisticated networks of inland container transport, and major nodes in these networks become the prototype of dry ports. Roso et al. [6] pointed out that on the backdrop of increased size of container vessels, dry ports play a key role in connecting seaports to the hinterland as they help relieve congestion at seaports while providing the hinterland with improved access to containerized ocean transport. As such, the location of dry ports became an import issue of research. Heaver et al. [7, 8], van Arjen Klink and van den Berg [9], Notteboom [10], Notteboom and Winkelmans [11], and Robinson [12] studied the relationship between ports and dry ports and further proposed different spatial configuration of dry ports. Yang [13] applied the method of multicriteria decision making to the problem of locating dry ports in the state of Texas, USA. Xu [14] developed a discrete choice model for locating an inland container depot, with the objective of profit maximization. In China, Xi et al. [15] proposed developing a dry port in the midwestern city of Xian. Guan [16] analyzed problems facing the development of dry ports in China. Cai and Chen [17] proposed 5 codevelopment patterns for seaports and dry ports. Wang [18] compared dry ports with container yards and constructed a discrete choice model for locating dry ports. Ma [19] developed a cellular automata program for locating dry ports that serve the Port of Tianjin. However, none of the existing research took into consideration the complex interaction between the government, the seaports, and the shippers when studying the problem of locating dry ports.

Key factors of a seaport group include port location, capacity, origin of shipments, and the cooperative and competitive relationships. If these factors are known, the task of optimizing the regional seaport-dry port system is to determine for the dynamic hinterland the number of dry ports, their locations and capacities, and the relationships among themselves as well as between them and the seaports. The regional configuration of dry ports is constrained by available candidate locations, transport access to these locations, and the shipping demand within the zone of influence of each location. The demand-supply relationship and the choice behavior of agents (seaports, dry ports, shippers, and carriers) need to be reasonably modeled. This research develops a location-allocation model for seaport-dry port system optimization, characterized by a probabilistic choice for shippers' use of dry ports and a partnership between seaports and dry ports. The research provides both a methodological approach for decision making and new insights on the relationship between seaports and the hinterland.

\section{The Location-Allocation Model for Seaport- Dry Port System Optimization}

For a regional seaport-dry port system focusing on exporting freight generated in the hinterland through seaports to the outside, there are two essential types of elements: nodes and links. Nodes include seaports, existing and planned dry ports, and hinterland origins of freight. Links connect the origins of

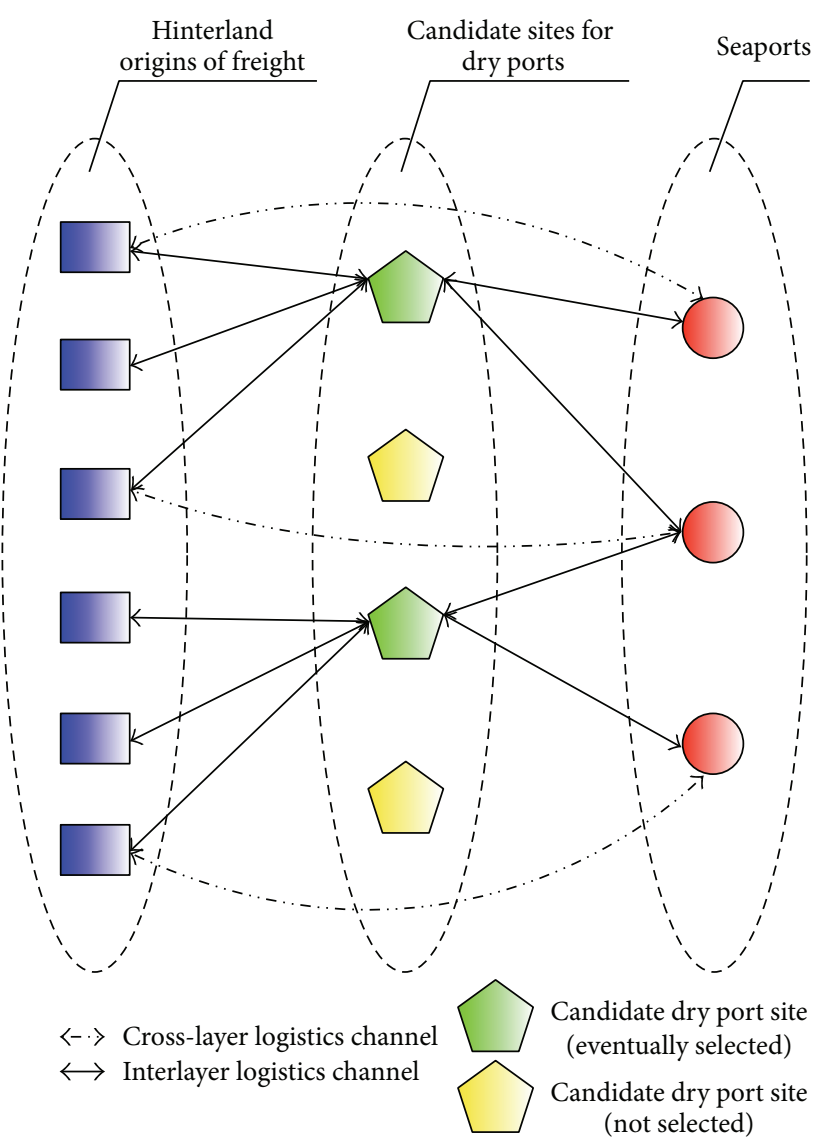

FigURE 1: Network flow on a regional seaport-dry port system.

freight to seaports, either directly or through dry-ports. This is shown in Figure 1.

2.1. Model Assumptions. For the abovementioned exportoriented regional seaport-dry port system with a single type of freight, the process of location-allocation is as follows: (1) the government constructs of dry ports and designates for each dry port the seaports it collaborates with; (2) shippers choose to route freight to a seaport, either directly or through a dry port. The government's action in step (1) must anticipate the choice of shippers in step (2), in order to minimize the overall regional logistics cost. Thus we have a locationallocation model, in which the government determines the number and the locations of dry ports, taking into consideration freight allocation by shippers. The objective is to minimize the regional logistics cost.

With regard to the relationship between dry ports and seaports, two scenarios are considered: (1) a dry port can partner with and send freight to any number of seaports and (2) a dry port can send freight to only one seaport. In both cases, a seaport can receive freight from multiple dry ports.

In addition, the following assumptions are made.

(a) The locations of the nodes (freight origins, seaports, and candidate sites for dry ports) are predetermined and known. 


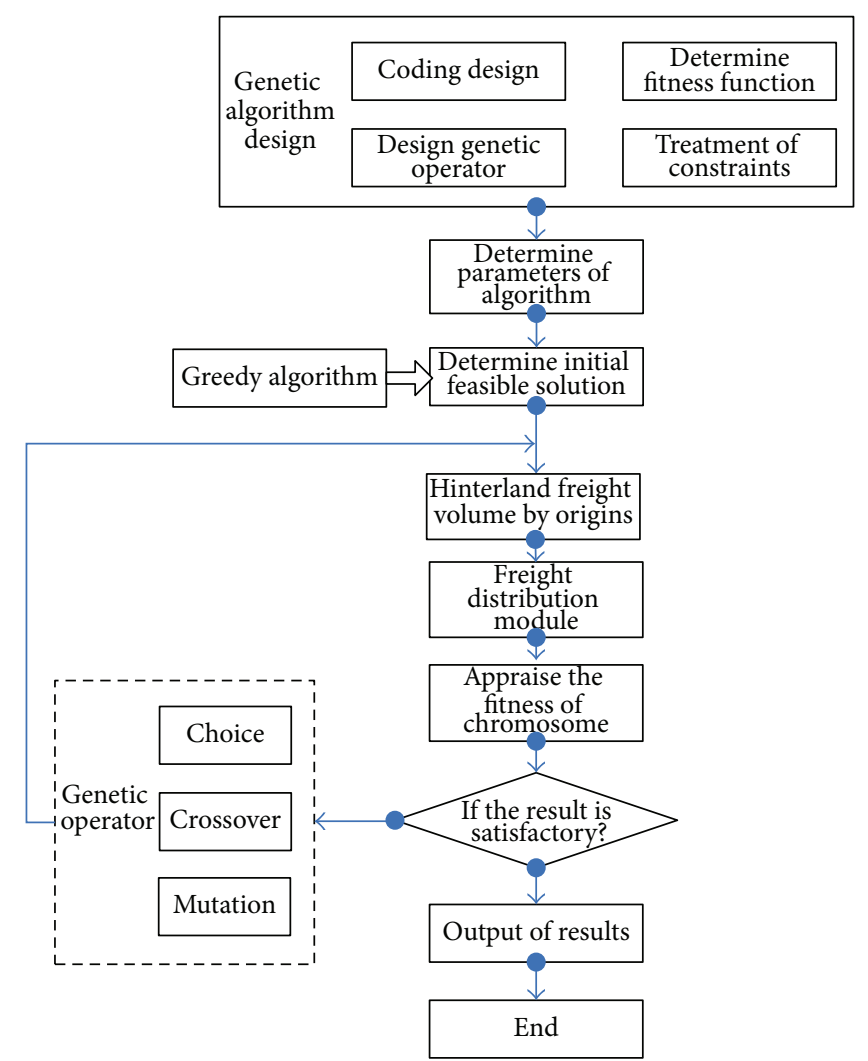

Figure 2: Process of the genetic algorithm.

(b) The transport links between the above nodes are predetermined and known.

(c) The freight volume originating from each hinterland origin is known, and freight must be exported through one of the seaports.

(d) The overall regional logistics cost includes the annual cost of transport, the amortized cost of setting up the dry ports, the cost of maintaining the transport links between dry ports and seaports, and the cost of maintaining the infrastructure at seaports.

(e) The unit transport cost on a link and the cost of setting up a dry port are not dependent on the freight volume, but the cost of maintaining a link or maintaining seaport infrastructure is dependent on the freight volume on the link or through the seaport.

(f) Any freight passes through at most one dry port.

\subsection{Model Formulation}

2.2.1. When a Dry Port Can Be Shared by Seaports. The programming model we develop consists of a model of system logistics cost minimization though determining from candidate dry port sites a subset to use, picking the collaborating seaports for each dry port, and allocating freight to different routes.
The model is as follows:

$$
\min Z\left(\psi_{k}, \varphi_{j k}\right)
$$

where

$$
\begin{gathered}
Z=\sum_{i, j}\left\{\left[\sum_{k \geq 1} \psi_{k} \varphi_{j k} Q_{i j k}\left(C_{i * k} l_{i * k}+\frac{C_{* j k} l_{* j k}}{m_{j}}\right)\right]\right. \\
\left.+\frac{Q_{i j 0} C_{i j 0} l_{i j 0}}{m_{j}}\right\} \\
+\sum_{k} \psi_{k} b_{k}+\sum_{j, k} \varphi_{j k}\left(b_{j k}+a_{1} Q_{j k}^{\theta_{1}}\right)+\sum_{j} a_{2} S_{j}^{\theta_{2}},
\end{gathered}
$$

s.t.

$$
\begin{gathered}
\psi_{k} \in\{0,1\}, \quad \forall k \geq 1, \\
\varphi_{j k} \in\{0,1\}, \quad \forall j, \forall k \geq 1, \\
Q_{j k}=\sum_{i} Q_{i j k}, \\
Q_{k}=\sum_{j} Q_{j k}, \\
S_{j}=\sum_{k} Q_{j k}, \\
P_{i j k}=\frac{e^{V_{i j k}}}{\sum_{j k} e^{V_{i j k}}}, \\
Q_{i j k}=D_{i} P_{i j k} .
\end{gathered}
$$

The subscripts $i, j$, and $k$ denote freight origins, seaports, and dry port candidate sites, respectively.

In the objective function, $\sum_{k \geq 1} \psi_{k} \varphi_{j k} Q_{i j k}\left(C_{i * k} l_{i * k}+\right.$ $\left.C_{* j k} l_{* j k} / m_{j}\right)+Q_{i j 0} C_{i j 0} l_{i j 0} / m_{j}$ is the transport cost for freight originating from $i$ and destined to $j$. $\sum_{k} \psi_{k} b_{k}$ is the amortized cost of setting up the dry ports, $\sum_{j, k} \varphi_{j k}\left(b_{j k}+a_{1} Q^{\theta_{1}}\right)$ is the cost for maintaining the transport links between all links from dry ports to seaports, and $\sum_{j} a_{2} S_{j}^{\theta_{2}}$ is the cost of maintaining the infrastructure at seaports.

The decision variables are $\psi_{k}$ and $\varphi_{j k} . \psi_{k}$ specifies if candidate site $k$ is used as a dry port. $\psi_{k}=1$ if site $k$ is used and 0 if not. $\varphi_{j k}$ specifies if port $j$ has a partnership with dry port $k$ so $j$ could receive freight from $k \cdot \varphi_{j k}=1$ if there is a partnership between $j$ and $k$ and 0 if not. Constraints (3) and (4) specify feasible values of $\psi_{k}$ and $\varphi_{j k}$.

$Q_{i j k}$ is the flow of freight from hinterland origin $i$ through dry port $k$ to seaport $j$. When $k=0, Q_{i j 0}$ is the flow of freight from hinterland origin $i$ directly to seaport $j$. The value of each $Q_{i j k}$ is determined in the expression (8) and (9). $D_{i}$ is the total volume of freight generated at hinterland origin $i$, and $P_{i j k}$ is the percentage of freight generated at $i$ that would be routed through dry port $k$ to seaport $j . V_{i j k}=-R_{i j k}$, where $R_{i j k}$ is the transport cost per unit volume unit distance of moving freight from source $i$ to seaport $j$ through dry port $k$. 


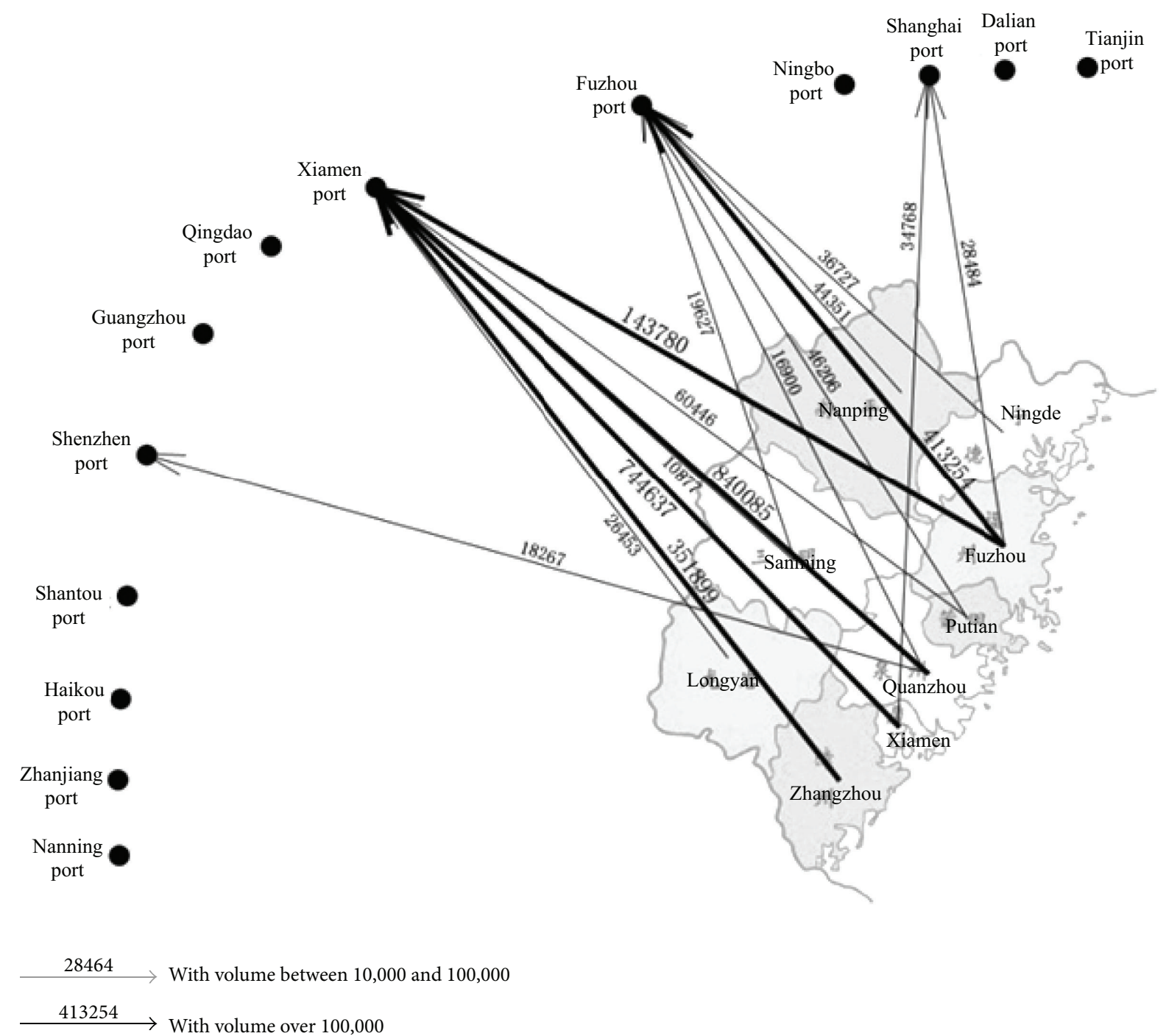

FIGURE 3: Export freight volumes between cities in Fujian province and various seaports.

Available dry ports and dry port-seaport partnerships given by the values of $\psi_{k}$ and $\varphi_{j k}$ are used to define feasible routes.

$Q_{j k}$ is the volume of freight sent by dry port $k$ to seaport j. $Q_{k}$ is the total volume of freight routed through dry port $k$. $S_{j}$ is the total volume of freight sent to seaport $j$. Constrains (5), (6), and (7) specify these relationships.

$l_{i * k}$ is the transport distance between hinterland origin $i$ and dry port $k . l_{* j k}$ is the transport distance between dry port $k$ and seaport $j . l_{i j 0}$ is the direct transport distance between hinterland origin $i$ and seaport $j . C_{i * k}, C_{* j k}$, and $C_{i j 0}$ are the transport cost per unit volume unit distance corresponding to the above three types of distances, respectively. $m_{j}$ is a parameter indicating seaport $j$ 's attractiveness to shippers, as shippers discount unit transport costs to seaports differently due to perceived differences in the levels of service at seaports. A more attractive seaport has a larger $m_{j}$.

Besides transport costs, the system logistics cost contains also handling costs and the costs related to setting up dry ports and their partnerships. As stated in assumption 7, unit handling cost at dry port $k$ is dependent on $Q_{j k}$, the freight volume it sends to each seaport, and unit handling cost at a seaport $j$ is dependent on $S_{j}$, the overall freight volume of seaport $j . a_{1}, a_{2}, \theta_{1}$, and $\theta_{2}$ are cost parameters. $b_{k}$ is the cost of amortized cost of setting up a dry port at candidate site $k$, and $b_{j k}$ is the cost of maintaining a partnership between dry port $k$ and seaport $j$. The values of these parameters can be established from expert survey or estimated from field data.

2.2.2. When Each Dry Port Is Dedicated to a Seaport. The model remains essentially the same, with one additional constraint added to the model:

$$
\sum_{j} \varphi_{j k}=\psi_{k}
$$

\section{Solution Algorithms}

The objective of regional seaport-dry port system optimization is to determine the quantity, size, and location of 


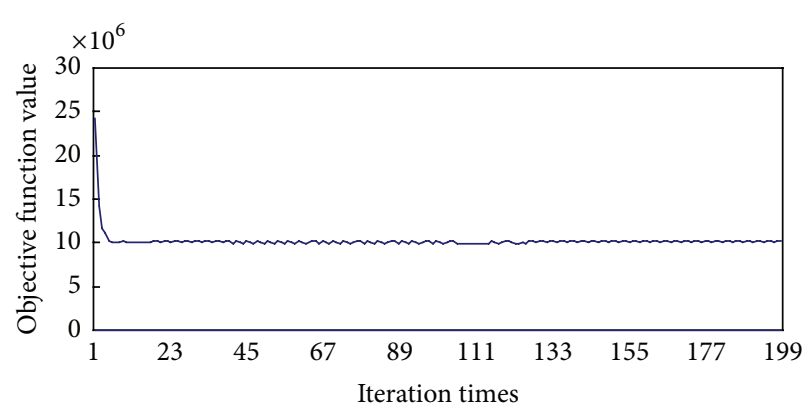

(a) Shared

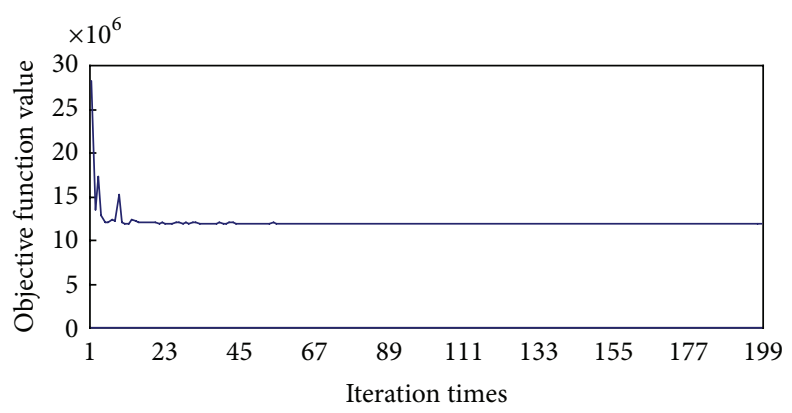

(b) Dedicated

FIgURE 4: The iteration process.

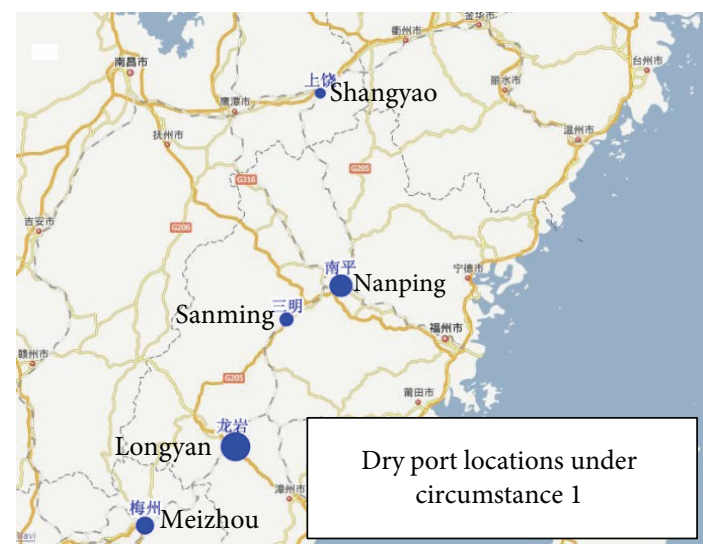

(a) Shared

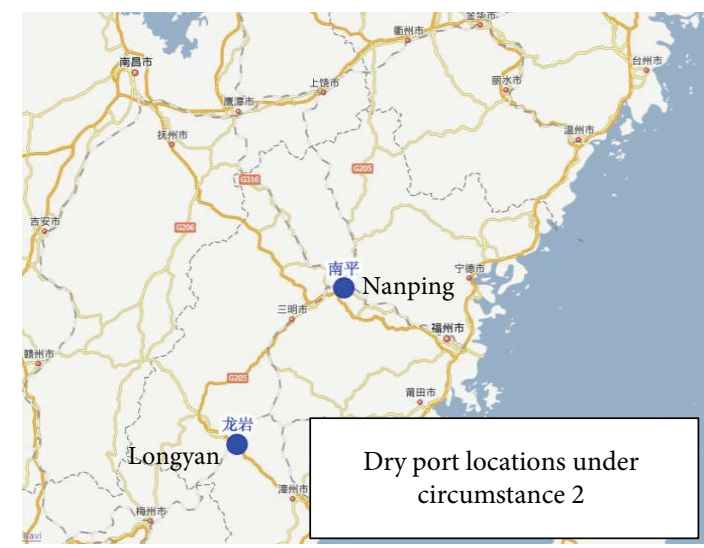

(b) Dedicated

Figure 5: Dry port locations.

the dry ports and the transport links between them and seaports so as to minimize region-wide logistics cost. In the programming model formulated above, the objective function is nonlinear, and the decision variables must take binary values. Thus common optimization techniques do not readily apply. Instead, a greedy algorithm and a genetic algorithm are combined to solve the optimization problem.

\subsection{Determination of an Initial Feasible Solution with a Greedy} Algorithm. A greedy algorithm is adopted to obtain a good feasible solution of the model. The basic idea of the algorithm is to start with the full network (i.e., setting up a dry port at each candidate location and linking each dry port to all seaports in the case of shared dry port or to its nearest seaport in the case of dedicated dry port) and then take out links one at a time to examine if the system logistics cost can be reduced, until no link can be taken out to further reduce the system logistics cost.

When each dry port can be shared by seaports, the steps are the following.

Step 1. Set up $m$ dry ports, where $m$ is the total number of candidate sites for dry ports, and link each dry port with $n$ seaports, where $n$ is the total number of seaports. Denote the current set of dry ports as SM and the set of links between dry
TABLE 1: Seaports and their attractiveness to shippers.

\begin{tabular}{lcc}
\hline No. & Name of seaport & Attractiveness to shippers \\
\hline 1 & Tianjin & 4.5 \\
2 & Dalian & 4.4 \\
3 & Shanghai & 10.0 \\
4 & Ningbo & 4.8 \\
5 & Fuzhou & 4.0 \\
6 & Xiamen & 4.3 \\
7 & Qingdao & 4.4 \\
8 & Guangzhou & 4.6 \\
9 & Shenzhen & 4.3 \\
10 & Shantou & 3.0 \\
11 & Haikou & 2.0 \\
12 & Zhanjiang & 3.0 \\
13 & Nanning & 1.0 \\
\hline
\end{tabular}

ports and seaports as SN. For dry port $k$ in SM, denote the set of links in SN that emanates from dry port $k$ as Sk. The links in Sk are ordered by unit transport cost on the link.

Step 2. Allocate the freight volume generated from hinterland origins to routes according to the expression (8) and (9), and calculate system logistics cost according to the model. 
TABLE 2: Hinterland freight origins in Fujian province.

\begin{tabular}{lcc}
\hline No. & Name of freight origin & Demand volume (tons/year) \\
\hline 1 & Fuzhou & 597646 \\
2 & Xiamen & 796707 \\
3 & Putian & 117423 \\
4 & Sanming & 33216 \\
5 & Quanzhou & 886176 \\
6 & Zhangzhou & 363424 \\
7 & Nanping & 52748 \\
8 & Ningde & 49893 \\
9 & Longyan & 30222 \\
\hline
\end{tabular}

TABLE 3: Candidate dry ports.

\begin{tabular}{lc}
\hline No. & Name of dry port \\
\hline 1 & Nanchang \\
2 & Changsha \\
3 & Ganzhou \\
4 & Nanping \\
5 & Sanming \\
6 & Longyan \\
7 & Jiujiang \\
8 & Shangrao \\
9 & Meizhou \\
10 & Yingtan \\
\hline
\end{tabular}

Step 3. Initialize $k=0$; denote $r$ as the number of members in set SM.

Step 4. Let $k=k+1$.

Step 5. Start from the link in Sk with the highest unit transport cost; examine the links in Sk one by one to see if any can be removed. If yes, remove that link from Sk and SN.

Step 6. Examine if the last step removed any link. If yes, go to Step 5.

Step 7. If Sk is empty, mark dry port $k$ from exclusion.

Step 8. If $k<r$, go to Step 4 .

Step 9. Remove all dry ports marked for exclusion from SM.

Step 10. Examine if from Step 4 to Step 9 removed any link from SN. If yes, go to Step 3.

Step 11. What remains in SM and $\mathrm{SN}$ is an initial feasible solution for the programming problem.

3.2. Genetic Algorithm for the Location-Allocation Model for Seaport-Dry Port System Optimization. With the genetic algorithm to optimize the regional seaport-dry port system, new solution is obtained through random transformation of current solutions. The basic idea is as follows: decide for the decision variables a coding scheme; then generate the initial population, of which individuals shall be corresponding to different dry port-seaport system configurations; use the expression (8) and (9) to obtain network flows and corresponding system logistics costs to evaluate the fitness of each individual. Conduct operations of choice, crossover, and genetic mutation to this population, and after several generations, the algorithm converges, and the resulting system configuration would be adopted as the optimal solution to the programming problem. In this research, real number coding is adopted for coding and the objective function of the problem is adopted as the fitness function. Genetic operations are conducted with the roulette wheel selection based on "ranking," and single point arithmetic crossover is adopted for crossover operations. Penalty factors are added to the fitness function to account for constraint violations.

The detailed process is shown in Figure 2; the steps of the algorithm are shown next.

Step 1 (set the parameters). Set the population size "pop_size," mutation rate $p_{m}$, the crossover rate $p_{c}$, the maximum number of iterations "Gen," and the initial generation $t=0$.

Step 2 (initialization). The initial population $P(t)$ with the size of "pop_size" is generated.

Step 3. Apply the allocation expression (8) and (9) to the chromosome in population $P(t)$ to obtain freight flows on the network.

Step 4. Apply the model's objective function to obtain the fitness of the scheme.

Step 5 (conduct genetic operations). Conduct hybrid and mutation operations with specified $p_{m}$ and $p_{c}$ values to generate next generation $C(t)$.

Step 6. Apply the allocation expression (8) and (9) to the chromosome in population $C(t)$ to obtain freight flows on the network.

Step 7. Calculate the fitness value of $C(t)$.

Step 8 (execute choice operation). In accordance with the roulette wheel method and the elite preservation strategy, obtain $P(t+1)$ of population size "pop_size" from $P(t)$ and $C(t)$.

Step 9 (termination conditions). If $t<$ Gen, then $t=t+$ 1; return to Step 5 to continue with the evolution operation process; if $t=$ Gen, terminate the algorithm and output the solution.

\section{Seaport-Dry Port System Optimization for Fujian Province}

Two seaports on the coast of Fujian province, Xiamen and Fuzhou, compete but also cooperate with other major Chinese coastal seaports to serve the hinterland regions of 
TABLE 4: Export volume (in tons/year) between cities in Fujian province and various seaports.

\begin{tabular}{lccccccccccccc}
\hline $\begin{array}{l}\text { Freight } \\
\text { origin }\end{array}$ & Tianjin & Dalian & Shanghai & Ningbo & Fuzhou & Xiamen & Qingdao & Guangzhou & Shenzhen & Shantou Haikou Zhanjiang Nanning \\
\hline Fuzhou & 327 & 124 & 28484 & 1117 & 413254 & 143780 & 1546 & 367 & 7338 & 58 & 11 & 0 \\
Xiamen & 945 & 186 & 34768 & 2775 & 460 & 744637 & 3681 & 349 & 8242 & 8 & 5 & 2 \\
Putian & 28 & 1 & 4048 & 320 & 46206 & 60446 & 983 & 5 & 5351 & 1 & 0 & 0 & 36 \\
Sanming & 177 & 1 & 882 & 100 & 19627 & 10877 & 80 & 0 & 974 & 0 & 0 & 0 & 497 \\
Quanzhou & 761 & 141 & 2932 & 1430 & 16900 & 840085 & 1047 & 292 & 18267 & 106 & 2 & 0 & 4213 \\
Zhangzhou & 126 & 42 & 3645 & 219 & 268 & 351899 & 619 & 330 & 3793 & 2188 & 2 & 16 & 277 \\
Nanping & 8 & 0 & 3387 & 278 & 44351 & 3657 & 74 & 9 & 829 & 1 & 0 & 0 & 153 \\
Ningde & 290 & 56 & 242 & 1878 & 36727 & 9574 & 115 & 5 & 759 & 167 & 15 & 1 & 64 \\
Longyan & 0 & 0 & 2148 & 7 & 43 & 26453 & 15 & 2 & 1466 & 41 & 0 & 0 & 46 \\
\hline
\end{tabular}

TABLE 5: Unit transport cost (in Yuan/ton) between cities in Fujian province and alternative dry ports.

\begin{tabular}{lcccccccccc}
\hline $\begin{array}{l}\text { Freight } \\
\text { origin }\end{array}$ & Nanchang & Changsha & Ganzhou & Nanping & Sanming & Longyan & Jiujiang & Shangrao & Meizhou & Yingtan \\
\hline Fuzhou & 49 & 73 & 50 & 20 & 25 & 32 & 56 & 40 & 44 & 40 \\
Xiamen & 60 & 71 & 36 & 33 & 27 & 18 & 69 & 62 & 27 & 50 \\
Putian & 55 & 81 & 52 & 31 & 26 & 24 & 64 & 49 & 42 & 49 \\
Sanming & 33 & 59 & 32 & 83 & 0 & 26 & 42 & 33 & 26 & 27 \\
Quanzhou & 53 & 75 & 41 & 27 & 29 & 24 & 62 & 54 & 35 & 47 \\
Zhangzhou & 52 & 66 & 32 & 33 & 27 & 109 & 61 & 62 & 26 & 46 \\
Nanping & 35 & 61 & 38 & 0 & 83 & 33 & 44 & 31 & 32 \\
Ningde & 57 & 83 & 60 & 30 & 28 & 38 & 66 & 33 & 54 & 51 \\
Longyan & 44 & 58 & 33 & 25 & 26 & 1 & 53 & 47 & 25 & 38 \\
\hline
\end{tabular}

the Fujian province. For this study, 13 seaports are considered: Tianjin, Dalian Shanghai, Ningbo, Fuzhou, Xiamen, Qingdao, Guangzhou, Shenzhen, Shantou, Haikou, Zhanjiang, and Nanning, as shown in Table 1. There are 9 hinterland freight origins in Fujian province: Fuzhou, Xiamen, Putian, Sanming, Quanzhou, Zhangzhou, Nanping, Ningde, and Longyan, as shown in Table 2. There are 10 candidate sites for dry ports: Nanchang, Changsha, Sanming, Ganzhou, Longyan, Nanping, Jiujiang, Meizhou, Yingtan, and Shangrao, as shown in Table 3. Annual export freight volumes from the hinterland origins are aggregated from customs data on export freight volumes between cities in Fujian province and the seaports (see Table 4 and Figure 3 ). The minimum unit transport costs between these locations are shown in Tables 5, 6, and 7. These units costs are in the unit of Yuan/ton, and they already account for 3 factors in the objective function: the cost per ton per unit distance, the transport distance, and the seaport attractiveness factor.

We look at both the case of shared dry ports and the case of dedicated dry ports. The values of other parameters in the objective function (i.e., $a_{1}, a_{2}, \theta_{1}, \theta_{2}, B_{k}$, and $B_{j k}$ ) used in this study are taken from a combination of expert survey and estimation of field data. Due to the economy of scale, $\theta_{1}$ and $\theta_{2}$ are usually greater than 0 but less than 1 .

(1) When the Dry Port Is Jointly Developed and Is Shared by Multiple Seaports. When no dry port is constructed, the total cost is $3.30839873 \times 10^{7}$. The initial solution of the model is obtained with the greedy algorithm. The second column of Table 8 shows the initial solution, under which the total cost is $2.4182488 \times 10^{7}$. For the genetic algorithm, we set the selection probability for the genetic operator at 0.8 , the crossover probability at 0.5 , and the mutation probability at 0.01 . The maximum number of iterations is 200; the iteration process is shown in Figure 4(a), and it converges to the optimum solution after 200 iterations. The fourth column of Table 8 shows the optimal solution; Figure 5(a) shows the resulting dry ports on the map. Under the optimal solution, the total cost is $1.000304 \times 10^{7}$.

(2) When the Dry Port Is Dedicated to a Seaport. When no dry port is constructed, the total cost is $3.30839873 \times 10^{7}$. The initial solution of the model is obtained with the greedy algorithm. The third column of Table 8 shows the initial solution, under which the total cost is $2.827592 \times 10^{7}$. For the genetic algorithm, we set the selection probability for the genetic operator at 0.8 , the crossover probability at 0.5 , and the mutation probability at 0.01 . The maximum number of iterations is 200; the iteration process is shown in Figure 4(b), and it converges to the optimum solution after 200 iterations. The fifth column of Table 8 shows the optimal solution. Figure 5(b) shows the resulting dry ports on the map. Under the optimal solution, the total cost is $1.194766 \times 10^{7}$.

From the above, we can see that development of dry ports dramatically reduces system logistics cost for hinterland origins in Fujian province. 
TABLE 6: Unit transport cost (in Yuan/ton) between cities in Fujian province and various seaports.

\begin{tabular}{|c|c|c|c|c|c|c|c|c|c|c|c|c|c|}
\hline \multirow{2}{*}{$\begin{array}{l}\text { Freight } \\
\text { origin }\end{array}$} & \multicolumn{13}{|c|}{ Seaport } \\
\hline & Tianjin & Dalian & Shanghai & Ningbo & Fuzhou & Xiamen & Qingdao & Guangzhou & Shenzhen & Shantou & Haikou & Zhanjiang & Nanning \\
\hline Fuzhou & 152 & 239 & 66 & 45 & 1 & 30 & 187 & 87 & 67 & 41 & 119 & 78 & 130 \\
\hline Xiamen & 160 & 226 & 83 & 65 & 29 & 1 & 138 & 57 & 48 & 22 & 100 & 142 & 104 \\
\hline Putian & 160 & 214 & 70 & 53 & 115 & 20 & 126 & 68 & 59 & 33 & 111 & 143 & 70 \\
\hline Sanming & 137 & 206 & 66 & 58 & 25 & 27 & 117 & 57 & 55 & 38 & 103 & 130 & 105 \\
\hline Quanzhou & 157 & 220 & 76 & 58 & 20 & 92 & 132 & 61 & 53 & 26 & 109 & 147 & 109 \\
\hline Zhangzhou & 156 & 220 & 85 & 68 & 33 & 66 & 137 & 54 & 46 & 20 & 98 & 138 & 102 \\
\hline Nanping & 139 & 202 & 60 & 52 & 20 & 33 & 113 & 63 & 61 & 44 & 109 & 132 & 111 \\
\hline Ningde & 136 & 199 & 55 & 38 & 102 & 28 & 111 & 85 & 73 & 47 & 125 & 112 & 129 \\
\hline Longyan & 148 & 217 & 84 & 76 & 32 & 18 & 128 & 49 & 46 & 28 & 96 & 82 & 96 \\
\hline
\end{tabular}

TABLE 7: Unit transport cost (in Yuan/ton) between alternative dry ports and various seaports.

Seaport
Dry port
Tianjin Dalian Shanghai Ningbo Fuzhou Xiamen Qingdao Guangzhou Shenzhen Shantou Haikou Zhanjiang Nanning

\begin{tabular}{llllllllllllll}
\hline Nanchang & 109 & 181 & 62 & 53 & 47 & 60 & 124 & 82 & 74 & 76 & 140 & 111 & 104 \\
Changsha & 136 & 203 & 94 & 91 & 78 & 96 & 130 & 57 & 68 & 99 & 120 & 91 & 78 \\
Ganzhou & 148 & 222 & 93 & 91 & 62 & 44 & 155 & 44 & 41 & 43 & 107 & 69 & 108 \\
Nanping & 139 & 202 & 66 & 52 & 20 & 33 & 113 & 63 & 61 & 44 & 109 & 97 & 111 \\
Sanming & 156 & 206 & 75 & 67 & 25 & 27 & 118 & 57 & 55 & 38 & 103 & 91 & 105 \\
Longyan & 148 & 217 & 84 & 76 & 32 & 18 & 128 & 49 & 46 & 27 & 96 & 82 & 96 \\
Jiujiang & 100 & 171 & 55 & 54 & 56 & 69 & 83 & 75 & 75 & 73 & 121 & 108 & 108 \\
Shangrao & 120 & 183 & 41 & 33 & 40 & 59 & 96 & 80 & 80 & 66 & 126 & 113 & 113 \\
Meizhou & 156 & 225 & 92 & 83 & 44 & 30 & 136 & 32 & 29 & 17 & 78 & 65 & 79 \\
Yingtan & 113 & 182 & 49 & 41 & 41 & 54 & 93 & 73 & 73 & 58 & 119 & 106 & 106 \\
\hline
\end{tabular}

TABLE 8: Initial solution and optimization result after 200 iterations.

\begin{tabular}{|c|c|c|c|c|}
\hline Dry port & $\begin{array}{c}\text { Dry port throughput } \\
\text { (shared) } \\
\text { (the initial solution) }\end{array}$ & $\begin{array}{l}\text { Dry port throughput } \\
\text { (dedicated) } \\
\text { (the initial solution) }\end{array}$ & $\begin{array}{c}\text { Dry port throughput } \\
\text { (shared) } \\
\text { (the optimal solution) }\end{array}$ & $\begin{array}{l}\text { Dry port throughput } \\
\text { (dedicated) } \\
\text { (the optimal solution) }\end{array}$ \\
\hline Nanchang & 0 & 0 & 0 & 0 \\
\hline Changsha & 0 & 0 & 0 & 0 \\
\hline Ganzhou & 0 & 0 & 0 & 0 \\
\hline Nanping & 97818.44531 & 105605.3281 & 412067.5 & 891146.75 \\
\hline Sanming & 63477.57422 & 127935.3594 & 31191.81445 & 0 \\
\hline Longyan & 387477.7813 & 378427.6563 & 1083868.75 & 878881.5 \\
\hline Jiujiang & 0 & 0 & 0 & 0 \\
\hline Shangrao & 1015.576355 & 0 & 72.5763855 & 0 \\
\hline Meizhou & 10148.79297 & 0.000772247 & 364213.125 & 0 \\
\hline Yingtan & 0 & 0 & 0 & 0 \\
\hline
\end{tabular}

\section{Conclusion}

With the increased competition between the regional seaport-dry port networks, optimizing system configuration has attracted attention of many researchers. The regional seaport- dry port system is a complex system. By focusing on the relationship between seaports and dry ports, this paper has developed a location-allocation model for regional seaportdry port system optimization and has proposed an efficient solution method for the programming problem. This paper 
provides justifications for developing dry ports at strategic locations and lays a foundation for future research on regional resource integration.

\section{Acknowledgments}

The paper is funded by the National Natural Science Foundation of China (Project no. 51009060), the Research Basis Project of Philosophy and Social Science of Jiangsu Province (09JD017), and the Priority Academic Program Development of Jiangsu Higher Education Institutions (Coastal Development Conservancy).

\section{References}

[1] J. H. Bird, The Major Seaports of the United Kingdom, Hutchinson, London, UK, 1963.

[2] B. Hoyle, Seaports and Development: The Experience of Kenya and Tanzania, Gordon and Breach Science, New York, NY, USA, 1983.

[3] T. E. Notteboom and J.-P. Rodrigue, "Port regionalization: towards a new phase in port development," Maritime Policy and Management, vol. 32, no. 3, pp. 297-313, 2005.

[4] J.-P. Rodrigue and T. Notteboom, "Foreland-based regionalization: integrating intermediate hubs with port hinterlands," Research in Transportation Economics, vol. 27, no. 1, pp. 19-29, 2010.

[5] CEMT, "Land access to sea ports: round table 113," Tech. Rep., CEMT, Paris, France, 2001.

[6] V. Roso, J. Woxenius, and K. Lumsden, "The dry port concept: connecting container seaports with the hinterland," Journal of Transport Geography, vol. 17, no. 5, pp. 338-345, 2009.

[7] T. Heaver, H. Meersman, F. Moglia, and E. van de Voorde, "Do mergers and alliances influence European shipping and port competition?" Maritime Policy and Management, vol. 27, no. 4, pp. 363-373, 2000.

[8] T. Heaver, H. Meersman, and E. van de Voorde, "Co-operation and competition in international container transport: strategies for ports," Maritime Policy and Management, vol. 28, no. 3, pp. 293-305, 2001.

[9] H. van Arjen Klink and G. C. van den Berg, "Gateways and intermodalism," Journal of Transport Geography, vol. 6, no. 1, pp. 1-9, 1998.

[10] T. E. Notteboom, "Consolidation and contestability in the European container handling industry," Maritime Policy and Management, vol. 29, no. 3, pp. 257-269, 2002.

[11] T. E. Notteboom and W. Winkelmans, "Structural changes in logistics: how will port authorities face the challenge?" Maritime Policy and Management, vol. 28, no. 1, pp. 71-89, 2001.

[12] R. Robinson, "Ports as elements in value-driven chain systems: the new paradigm," Maritime Policy and Management, vol. 29, no. 3, pp. 241-255, 2002.

[13] H. Yang, Dry Port Location Model Under Trans Texas Corridor Concept, The University of Texas, 2005.

[14] Y. Xu, A Discrete Choice Based Facility Location Modal for Inland Container Depot, West Virginia University, Morgantown, WVa, USA, 1999.

[15] P. Xi, G. Yan, and H. Cao, "Assumption on establishment of international port in western China-'xi'an dry port,' Tangdu Journal, vol. 17, no. 4, 2001.
[16] F. Guan, Research on Dry Port Development Trend and Size and Structure of Home Port Storage Yard, Dalian Maritime University, 2008.

[17] Y. Cai and N. Chen, "Research on linkage development of dry port and coastal port," Port Perspective, no. 10, pp. 26-31, 2009.

[18] H. Wang, Construction of "Dry Port" and Application of Discrete Choice Theory in Site Selection, Shanghai Maritime University, 2004.

[19] W. Ma, Strategic Research on Development of Dry Port by Tianjin Port, Tianjin University, 2009. 


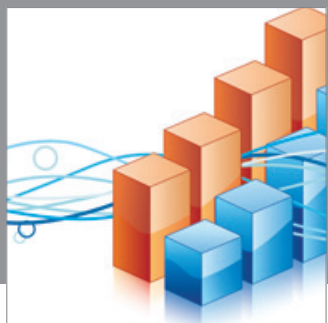

Advances in

Operations Research

mansans

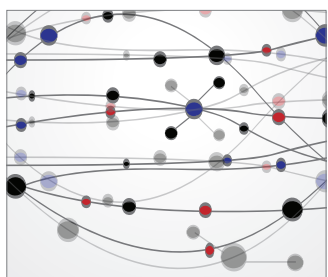

The Scientific World Journal
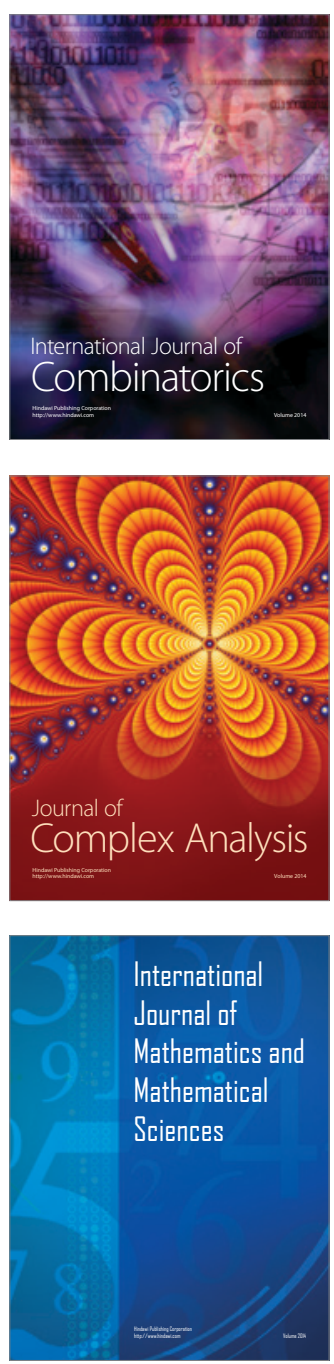
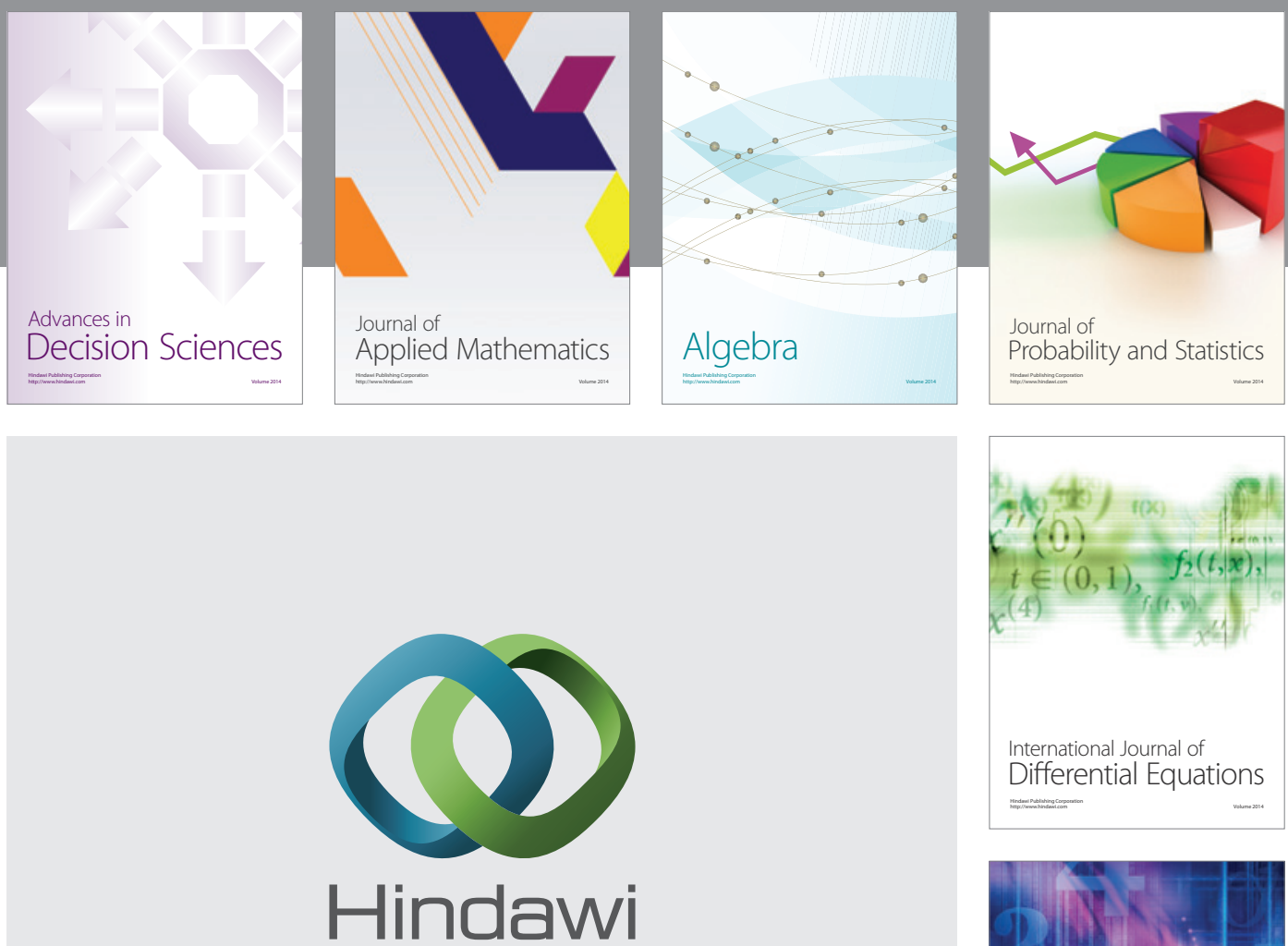

Submit your manuscripts at http://www.hindawi.com
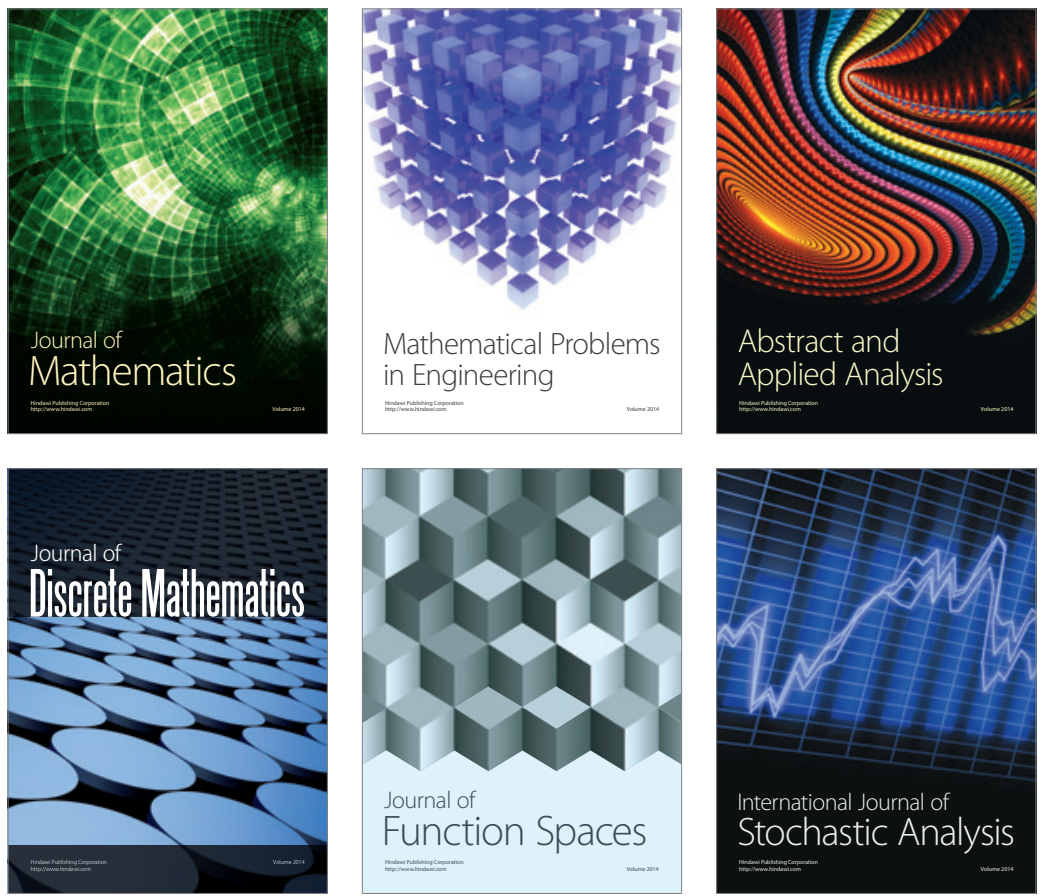

Journal of

Function Spaces

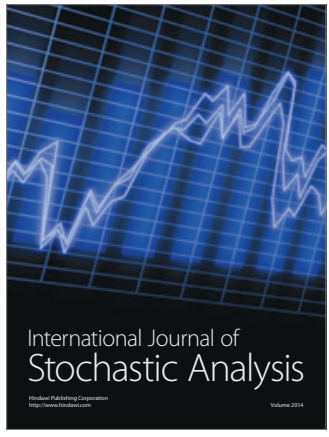

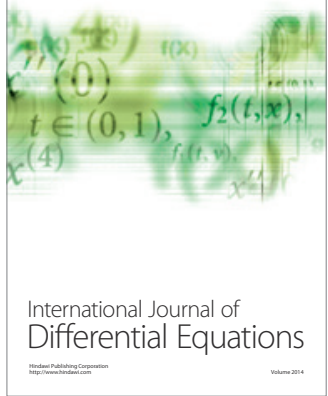
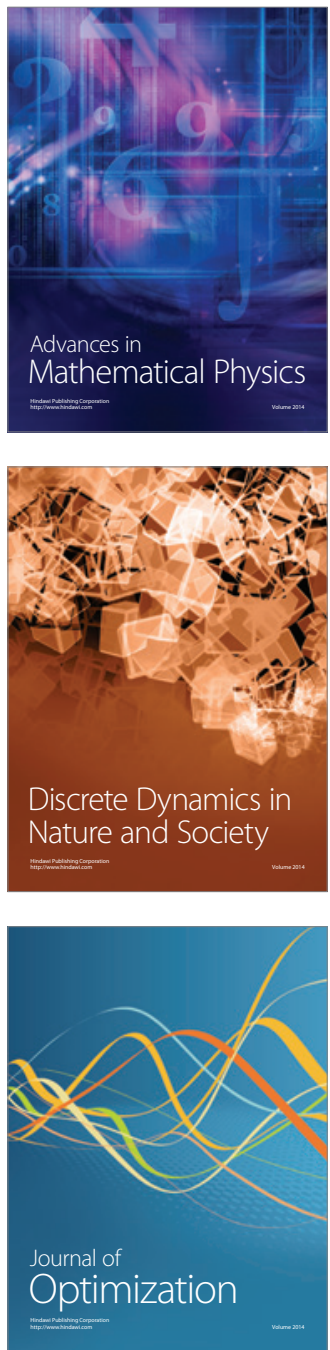